IRA-International Journal of Management \& Social Sciences

ISSN 2455-2267; Vol.03, Issue 03 (2016)

Institute of Research Advances

http://research-advances.org/index.php/RAJMSS

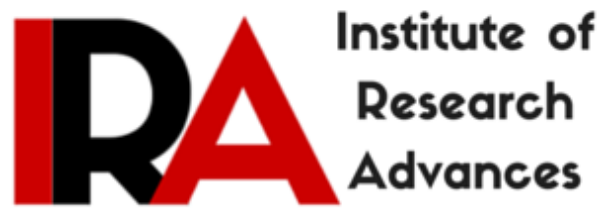

\title{
Emotional Maturity and Loneliness as Correlates of Life Satisfaction among Adolescents
}

\author{
${ }^{1}$ Nimmy Johns, \\ IIIrd BSc. Psychology, U. C. College, Aluva, \\ Ernakulam Dist. Kerala State, India. \\ ${ }^{2}$ Jerry P Mathew, \\ IIIrd BSc. Psychology, U. C. College, Aluva, \\ Ernakulam Dist. Kerala State, India. \\ ${ }^{3}$ Dr. Seena M Mathai, \\ Asst Professor, U. C. College, Aluva, \\ Ernakulam Dist. Kerala State, India.
}

DOI: http://dx.doi.org/10.21013/jmss.v3.n3.p16

\section{How to cite this paper:}

Johns, N., P Mathew, J., \& M Mathai, D. (2016). Emotional Maturity and Loneliness as Correlates of Life Satisfaction among Adolescents. IRA-International Journal of Management \& Social Sciences (ISSN 2455-2267), 3(3).

doi:http://dx.doi.org/10.21013/jmss.v3.n3.p16

(C) Institute of Research Advances

\section{(cc) EY-NC}

This works is licensed under a Creative Commons Attribution-Non Commercial 4.0 International License subject to proper citation to the publication source of the work.

Disclaimer: The scholarly papers as reviewed and published by the Institute of Research Advances (IRA) are the views and opinions of their respective authors and are not the views or opinions of the IRA. The IRA disclaims of any harm or loss caused due to the published content to any party. 
Emotions which are considered as a basic factor of all relationships 1 are very powerful and to a very great extent they control our behaviour, thoughts and all other aspects of life. The behaviour and thought processes are directly influenced by the past experiences and early developmental stages. Emotion is the feeling aspect of consciousness characterized by a physical aspect like physical arousal, behaviours that reveal emotion to the outside world, and an inner awareness of feelings. Healthy emotions motivate us and give us energy for appropriate action. Unhealthy emotions are either overly intense or suppressed.

Smiston in 1974 defined "Emotional maturity is a process in which the personality is continuously striving for greater sense of emotional health, both intra-physically and intra-personally" (as cited in Singh \& Bhargava, 1990). Kaplan and Baron describes a emotionally mature person as having the capacity to withstand delay in satisfaction of needs, ability to tolerate a reasonable amount of frustration, has belief in long-term planning and is capable of delaying or revising expectations in terms of demands of situation, has capacity to make effective adjustment with themselves, members of family, his peers in the school, society and culture. Maturity is not only the capacity for these attitudes and functioning but also it is the ability to enjoy them fully (as cited in Singh \& Bhargava, 1990). According to Hollingworth (1928) an emotionally mature person will be capable of responding in gradation or degree of emotional responses, he does not respond in all or none fashion, but keeps within bounds. He will be able to delay his responses as controlled with the impulsiveness of young child. And he will also be able to handle selfpity (as cited in Singh \& Bhargava, 1990).

According to Cole (1944) the most outstanding feature of emotional maturity is ability to bear tension. Other features are an indifference towards certain stimuli that affect the child or adolescent and leads to development of moodiness or sentimentality. Emotionally mature person have the capacity for fun and recreation (as cited in Singh \& Bhargava, 1990). According to McKinney (1960) "the characteristics of an emotionally mature are heterosexuality, appreciation of attitude and behaviour of others, tendency to adopt the attitude and habits of others and capacity to delay his own responses" (as cited in Singh \& Bhargava, 1990). According to Seoul (1951), if the emotional development of the individual is relatively complete, his adaptability is high, regressive tendencies are low, and his vulnerability is minimal (as cited in Singh \& Bhargava, 1990).

There are different levels for emotional maturity; the first level of emotional maturity is basic emotional responsibility, at this stage the person realize that he/she can no longer view this/her emotional states as the responsibility of external forces; the second level is emotional honesty, it is the willingness of the person to know their own feelings, this is a necessary step to self-understanding and acceptance; next level is emotional openness, it concerns the person's willingness and skills in sharing their feelings in an appropriate manner and at appropriate time; next level is emotional assertiveness, at this level the person shows positive self-expression, the primary goal here is to ask for and receive the nurturing that one needs; next level is emotional understanding, persons on this level understands the actual cause and effect process of emotional responsibility and emotional irresponsibility; the last level of emotional maturity is emotional detachment, at this level the person lives without burden of self-concepts, selfimages etc.

The five broad factors of emotional immaturity are emotional instability, emotional regression, social maladjustment, personality disintegration and lack of independence. Emotional instability is explained as lack of capacity to dispose off problems, irritability needs, vulnerability, stubbornness and temper tantrums. Emotional regression is abroad group of factors which includes feeling of inferiority, restlessness, hostility, aggressiveness and self-centredness. Social maladjustment is a person's lack of social adaptability, hatred, and the person will be boasting, liar and lazy. The feature of personality disintegration are reaction, phobias formation, rationalization, pessimism, immorality etc. and a person with personality disintegration experience inferiority and so react to environment through aggressiveness, destruction and has distorted sense of reality. A person with lack of independence show parasitic 
dependence on others is egoistic and lacks objective interests. People view them as an unreliable person (Mohsin, 1960).

A study conducted on emotional maturity and coping strategies among students pursuing rehabilitation studies by Wagde \& Ganaie (2013) found that less emotionally mature persons tend to prefer rather primitive and often inefficient coping methods, while more mature people preferred more sophisticated and useful methods. Another study by Singh (2013) on gender on social and emotional maturity of senior school adolescents found that girls tend to score more on social adequacy component of social maturity while boys scored ore on social adjustment component of emotional maturity. A study done by Pastey \& Aminbhavi (2006) on impact of emotional maturity on stress and self-confidence of adolescents found that adolescents with high emotional maturity have high stress and self-confidence.

Kumar (2014) on the topic emotional maturity of adolescent students in relation to their family relationship found that there is a significant difference in emotional maturity of boys and girls and it is also influenced by their family relations. Wan \& Masih (2015) conducted a study on emotional maturity across gender and level of education done on university students found that emotional maturity varies with level of education and women are more emotionally immature than men.

Loneliness is the distress that results from discrepancies between ideal and perceived social relationships or it can be described as the distressing feeling that one experiences when one's social relationships are perceived as being less satisfying than that is desired. Loneliness has been explained differently over the time. One theory of loneliness holds that deficiencies in specific provisions of social relationships contribute to specific type of loneliness feelings. Absence of reliable attachment figure is also associated with feelings of emotional loneliness such as anxiety, desolation, and insecurity(Weiss, 1973). Another theory holds that loneliness arises from social skill deficits and personality traits that impair the formation and maintenance of social relationships. Social skills research has shown that loneliness is associated with more self-focus, poorer partner attention skills, a lack of self-disclosure to friends, especially among females, and less participation in organized groups, especially among males. Personality research has shown that loneliness is associated with shyness, neuroticism, and depressive symptoms, as well as low self-esteem, pessimism, low conscientiousness, and agreeableness (Marangoni\& Ickes, 1989). Studies of loneliness have shown that mental representations of our connections with others are characterized by individual, relational, and collective dimensions. At the individual level, feelings of isolation and low self-worth are precluded when people feel comfortable with themselves and their fit in a social world. At the relational level, feelings of interpersonal connectedness are fostered in close dyadic relationships. At the collective level, feelings of group identification and cohesion satisfy a need for belonging. This three-dimensional representation of loneliness holds in young adults and across gender and racial/ethnic lines in middle age adults, suggesting universality to this representational structure of the social self.

Loneliness can also be experienced, as a temporary state that resolves when life circumstances resolve and chronically, as a trait-like characteristic that results from an interaction between life circumstances and a genetic bias to experience feelings of isolation. Once loneliness is triggered, it generates a defensive form of thinking, a "lonely" social cognition which can make it look like a mountain. Lonely people tend to be more anxious, pessimistic, and fearful of negative evaluation than people who feel good about their social lives, and are therefore more likely to act and relate to others in ways that are anxious, negative, and self-protective, which leads paradoxically to self-defeating behaviours. Researches show that lonely individuals are less trusting of others and believed that they were less trusted by others. In essence, lonely individuals exercised self-protective behaviours that prevented them from enjoying the positive, cooperative interactions that were theirs to be had. Not only do the lonely contribute to their own negative reality, but others begin to view them more negatively and begin to act accordingly. 
Many studies were conducted to know if there is any gender difference in the variable loneliness. Cramer \& Neyedley (1998) conducted a study on sex Differences in Loneliness: The Role of Masculinity and Femininity and found that males tend to be lonelier than females but they are reluctant to admit it. This is supported by studies conducted by Bory \& Perlman (1985), Wiseman, Guttfreund \& Lurie (1995) and by Stokes \& Levin (1986). This indicates that men and women use different standards in evaluating whether they are lonely. It is suggested that men may use more group-oriented criteria in evaluating loneliness, whereas women focus more on the qualities of dyadic relationships.

Diener et.al. (2008) on Reputation, Loneliness, Satisfaction with Life and Aggressive Behavior in Adolescence found that loneliness and life satisfaction mediate the relationship between adolescents' reputation and their aggressive behavior.

Life satisfaction is the way persons evaluate their lives and how they feel about where they are going in the future. It is a measure of well-being and may be assessed in terms of mood, satisfaction with relations with others and with achieved goals, self-concepts, and self-perceived ability to cope with daily life. It is having a favorable attitude of one's life as a whole rather than an assessment of current feelings. Life satisfaction cans reflect experiences that have influenced a person in a positive way. These experiences have the ability to motivate people to pursue and reach their goals. There are two kinds of emotions that may influence how people perceive their lives. Hope and optimism both consist of cognitive processes that are usually oriented towards the reaching of goals and the perception of those goals. Additionally, optimism is linked to higher life satisfaction, whereas pessimism is related to symptoms in depression. The people who are old aged are found to be satisfied in their life. The experiments shows that life satisfaction grows as people become older because they become wiser and more knowledgeable, so they begin to see that life will be better as they grow older and understand the important things in life more.

In 2013, Deniz et.al. conducted a study on Parental Attitude Perceived by University Students as Predictors of Subjective Well-Being and Life Satisfaction and found that, there is a positive significant relationship between democratic parental attitude and subjective well-being and life satisfaction scores; negative relation between protective and authoritarian parental attitude and subjective well-being and life satisfaction scores. Another study by Salimi (2011) on Emotional Loneliness and Life Satisfaction indicated that social and emotional loneliness were significant negative predictors of the life satisfaction, however emotional loneliness was stronger predictor, rather than social loneliness.

Huo \&Kong (2013) tried to identify the Moderating Effects of Gender and Loneliness on the Relationship Between Self-esteem and Life Satisfaction in Chinese University Students, and found that both high and low self-esteem group had low level of life satisfaction when loneliness was high. Likewise Bozorgpour, and Salimi, (2012) on State Self-Esteem, Loneliness and Life Satisfaction found emotional loneliness as a strong negative predictor of satisfaction with life. Tümkaya, Aybek, and Çelik.(2008) tried to verify if there is any gender difference on students' life satisfaction and loneliness level in a sample of Turkish students and found that the male students' loneliness level is higher than the female students' loneliness level and that there is no significant difference between male and female students' life satisfaction. They also found that there is a negative correlation between life satisfaction and loneliness level.

\section{Need and Significance}

Loneliness and dissatisfaction with life are some common complaints that we hear from college students and it has also been observed that they behave in an emotionally immature way. These loneliness and dissatisfaction with life can significantly affect a person in regard to his/her self -concept, self esteem, perception of world or others or their attitudes towards the life. Emotional maturity, company of others and satisfaction with life is essential for a person to live up to his/her potential, for self-growth and self- discovery. In this context this study intends to find out whether there is any relation between 
emotional immaturity, loneliness and satisfaction with life and whether gender difference plays a role in it.

\section{Aim}

The present study aims to examine whether there is any relationship between emotional maturity, loneliness and life satisfaction and whether there is any gender difference in the above mentioned variables.

\section{Method}

Methods outlines the way the research problem has been formulated and the procedures adopted to test the stated hypothesis. The sample consisted of 180 students of age 18-21 randomly selected form different colleges of Ernakulum district of Kerala. The participants included 90 males and 90 females. Emotional maturity was assessed using Emotional Maturity Scale (EMS) developed by Singh and Bhargava (1990). The test consists of 5 component parts emotional instability, emotional regression, emotional maladjustment, personality disintegration and lack of independence. The test- retest reliability of the scale is 0.75 and the internal consistency is 98 . The validity of the scale is 0.64 . Loneliness was assessed using Revised UCLA Loneliness Scale (RULS) developed by Russell, Peplan, and Cutrona (1980). The RULS have a good internal consistency with a alpha of 0.94 and has a good concurrent validity with a number of mood and personality measures and particularly with a self-labelling loneliness index. Life satisfaction was assessed using Satisfaction With Life Scale (SWLS) developed by Diener, Emmons, Larsen and Griffin (1985). SWLS have a good internal consistency with an alpha of 0.87 . The instrument has excellent test-retest reliability with a correlation of 0.82 for a two month period. The obtained data was analysed using SPSS version 16, The analysis include ' $t$ ' test, correlation and regression. The obtained results are discussed in the following session.

\section{Result and Discussion}

Through the present study, the investigators have attempted to explore whether there is any significant relationship between, one's emotional maturity and the loneliness experienced also explored whether the above mentioned variables played any role in the satisfaction of life, among under graduates and whether there is any gender difference in the variables. The data obtained from the participants were scored appropriately and analysed using ' $t$ ' test, correlation and regression and the obtained results are discussed in following sessions. 
Table 1: The ' $t$ ' value obtained for males and females in the dimensions of emotional immaturity, loneliness and satisfaction with life

\begin{tabular}{cllccc}
\hline \multirow{2}{*}{ Variables } & Group & $\mathrm{N}$ & Mean & Std. Deviation & 't' value \\
\hline Emotional instability & Females & 90 & 24.15 & 6.08 & \multirow{2}{*}{0.06} \\
& Males & 90 & 24.22 & 6.89 & \\
Emotional Regression & Females & 90 & 21.08 & 5.92 & \multirow{2}{*}{1.58} \\
& Males & 90 & 22.64 & 7.20 & \\
Social Maladjustment & Females & 90 & 20.31 & 5.04 & \multirow{2}{*}{$3.25^{* *}$} \\
& Males & 90 & 22.96 & 5.88 & \\
Personality & Females & 90 & 18.84 & 5.27 & \multirow{2}{*}{$3.29^{* *}$} \\
Disintegration & Males & 90 & 21.67 & 6.23 & \\
Lack of Independence & Females & 90 & 18.68 & 7.56 & \multirow{2}{*}{1.03} \\
Emotional Immaturity & Males & 90 & 19.67 & 4.96 & \\
& Females & 90 & 101.94 & 21.10 & $2.56^{* *}$ \\
Loneliness & Males & 90 & 110.77 & 25.03 & \\
& Females & 90 & 39.20 & 9.08 & \multirow{2}{*}{0.75} \\
Satisfaction with Life & Males & 90 & 38.11 & 10.43 & \multirow{2}{*}{0.98} \\
\hline ** Significance at & Females & 90 & 23.66 & 7.70 & \\
\hline
\end{tabular}

The above table shows that there is a significant gender difference in the dimensions of emotional immaturity, social maladjustment, personality disintegration and total emotional immaturity at 0.05 level and other dimensions do not show any significant gender difference. Males are found to have higher levels of emotional immaturity, social maladjustment and personality disintegration in the sample under study. This indicates that males have less capacity to withstand delay in satisfaction of needs, not able to tolerate frustration, have difficulty to control their emotions, are more judgemental and reactive that females. The high score of males in the maturity dimension social maladjustment suggest that they lack social adaptability, are seclusive but boasting, lies and shirk more than females. Male's higher score for dimension personality disintegration than females suggest that they suffer more from feelings of inferiority and hence react to environment through aggressiveness, destruction and have distorted sense of reality.

This study showed both males and females as having similar levels of loneliness and satisfaction with life. This is contradictory to the findings by Cramer \& Neyedley (1998), Bory \& Perlman and Stokes \& Levin (1986) and Wiseman, Guttfreund \& Lurie (1995). Even though men and women use different standards in evaluating whether they are lonely it is not reflected in this sample. But it is suggested that men may use more group-oriented criteria in evaluating loneliness, whereas women focus more on the qualities of dyadic relationships. 
Table 2: Relationship of dimensions of emotional maturity with loneliness and satisfaction with life.

\begin{tabular}{lcc}
\hline \multicolumn{1}{c}{ Variables } & Loneliness & Satisfaction with \\
& $.470^{* *}$ & $-.263^{* *}$ \\
Emotionally Unstable & $.446^{* *}$ & $-.302^{* *}$ \\
Emotional Regression & $.390^{* *}$ & $-.209^{* *}$ \\
Social maladjustment & $.364^{* *}$ & $-.260^{* *}$ \\
Personality Disintegration & $.203^{* *}$ & -.048 \\
Lack of Independence & $.517^{* *}$ & $-.267^{* *}$ \\
Emotional Immaturity & 1 & $-.395^{* *}$ \\
Loneliness & 1 &
\end{tabular}

Significance at 0.05 level \&** significance at 0.01 level

From the above table it is clear that satisfaction with life shows a significant negative relationship with emotional immaturity and its dimensions except lack of independence, and with loneliness. Life satisfaction is the way persons evaluate their lives and how they feel about where they are going in the future. A person who is emotionally immature, have emotional regression, emotional instability, social maladjustment and personality disintegration won't be able to perceive positively and their life will be filled with distress and loneliness which in turn result in their unsatisfied life.

Lonely people tend to be more anxious, pessimistic, and fearful of negative evaluation than people who feel good about their social lives, and are therefore more likely to act and relate to others in ways that are anxious, negative, and self-protective, which leads paradoxically to self-defeating behaviours and it is the distress that results from discrepancies between ideal and perceived social relationships, these together can make people feel less satisfied of their life. The results are supported by a study by Bozorgpour and Salimi (2012) indicating emotional loneliness as a strong negative predictor of satisfaction with life. Tümkaya, Aybek and Çelik (2008) also supported the results from their study showing a negative correlation between life satisfaction and loneliness level.

Table 3.Regression table of dimensions of emotional maturity and loneliness with subjective wellbeing

\begin{tabular}{lcccc}
\hline \multicolumn{4}{c}{ Model Summary } \\
\hline Model & $\mathrm{R}$ & R Square & $\begin{array}{c}\text { Adjusted R } \\
\text { Square }\end{array}$ & $\begin{array}{c}\text { Std. Error of the } \\
\text { Estimate }\end{array}$ \\
1 & $.464^{\mathrm{a}}$ & .215 & .183 & 6.41296 \\
\hline a. Predictors: (Constant), Loneliness, Lack of Independence, Social \\
Maladjustment, Emotional Instability and regression, Personality \\
disintegration, Total emotional maturity.
\end{tabular}




\begin{tabular}{llccccc}
\hline & \multicolumn{7}{c}{ Unstandardized Coefficients } & \multicolumn{2}{c}{$\begin{array}{c}\text { Standardized } \\
\text { Coefficients }\end{array}$} \\
Model & & $\mathrm{B}$ & Std. Error & Beta & $\mathrm{t}$ & Sig. \\
\hline 1 & (Constant) & 34.821 & 2.512 & & 13.862 & .000 \\
& EU & -.170 & .138 & -.155 & -1.227 & .221 \\
& ER & -.386 & .144 & -.361 & -2.689 & .008 \\
& SM & -.198 & .150 & -.157 & -1.319 & .189 \\
& PD & -.381 & .148 & -.319 & -2.577 & .011 \\
& LI & .010 & .091 & .009 & .111 & .912 \\
& Total & .211 & .088 & .699 & 2.405 & .017 \\
& RULS & -.252 & .058 & -.347 & -4.352 & .000 \\
\hline
\end{tabular}

Dependent Variable: Satisfaction with life

The regression table indicates that $21.5 \%$ of satisfaction with life is predicted by the variables emotional regression, personality disintegration and loneliness which is significant at 0.05 level. Emotional regression includes feelings of inferiority, restlessness, hostility, aggressiveness and selfcenteredness. Personality disintegration refers to feelings of inferiority and reacting to environment through aggressiveness, destruction and distorted sense of reality. Loneliness is the distress that results from discrepancies between ideal and perceived social relationships and lonely people tend to be more anxious, pessimistic, and fearful of negative evaluation than people who feel good about their social lives, and are therefore more likely to act and relate to others in ways that are anxious, negative, and selfprotective, which leads paradoxically to self-defeating behaviours. Loneliness is the distress that results from discrepancies between ideal and perceived social relationships. These feeling together lead to lowered satisfaction with life. This is supported by Salimi (2011) on Emotional Loneliness and Life Satisfaction indicating social and emotional loneliness as significant negative predictors of the life satisfaction. However emotional loneliness was stronger predictor, rather than social loneliness. Loneliness was aslo found to mediate the relationship between Self-esteem and satisfaction with life (Huo \&Kong, 2013) and hence it is important to give them psychological aid to make these people identify these misperceptions of them and thereby becoming more satisfied about their own lives.

\section{Conclusion}

The present study was aimed to examine the relationship between emotional maturity, loneliness and life satisfaction and whether there is any gender difference in the above mentioned variables.

Male are found to be significantly higher in the variables emotional immaturity, social maladjustment and personality disintegration than females. It is also found that there is a significant positive relation between emotional immaturity and loneliness and satisfaction with life has a significant negative correlation with emotional immaturity and loneliness. $21.5 \%$ of satisfaction with life is predicted by emotional regression, personality disintegration and loneliness.

\section{Limitations}

Like other studies this study is also not free of limitations. The sample size of the study was small and the influence of other variables like economic status, parenting styles etc. was not taken into consideration in the study.

\section{Implications}

The study implies that emotional immaturity can lead to feelings of loneliness among college students and it also implies that emotional immaturity and loneliness together influence the person's satisfaction with life. Loneliness and emotional immaturity arise most of the time as a result of distorted 
perceptions and cognitions these can lower the individual's self-esteem and make them pessimistic. Hence it is important to assist them with proper care and nurturing to individuals at early ages itself to empower them to self-growth and self-discovery.

\section{REFERENCES}

Akhunlar, M. N. (2010). An investigation about the relationship between life Satisfaction and loneliness of nursing students in Uşak University. Procedia - Social and Behavioral Sciences, Vol.5(12), Pp. 2409-2415. Retrieved 23 March, 2016, from http://dx.doi.org/10.1016/j.sbspro.2010.07.472

Bernard, H. W. (1965). Psychology of Learning and Teaching. New York: McGraw Hill Book Co.

Bory, S. \& Perlman, D. (1985). Gender Differences in Loneliness. Personality and Social

Psychology Bulletin, 11(1), 63-74. Retrieved 12 March, 2016, from

http://dx.doi.org/10.1177/0146167285111006

Bozorgpour, F \& Salimi, A. (2012). State Self-Esteem, Loneliness and Life Satisfaction . Procedia -Social and Behavioral Sciences, Vol.69(12), 2004-2008.Retrieved on $20^{\text {th }}$ October, 2015, from, http://dx.doi.org/10.1016/j.sbspro.2012.12.157

Cramer, K. M. \& Neyedley, K. A. (1998). Sex Differences in Loneliness: The Role of Masculinity and Femininity. Sex Roles, Vol.38(7), Pp.645-653. Retrieved on 23 February, 2016, from http://dx.doi.org/10.1023/A:1018850711372

Diener, E.D., Emmons, R. A., Larsen, R.J., \& Griffin, S. (1985). The Satisfaction With Life Scale. Journal of Personality Assessment, 49(1), 71-75. Retrieved 23 September, 2016, from http://dx.doi.org/10.1207/s15327752jpa4901_13

Hou, Y \& Kong, F. (2013). Moderating Effects of Gender and Loneliness on the Relationship

Between Self-esteem and Life Satisfaction in Chinese University Students. Social Indicators Research, Vol.118(1), Pp.305-314. Retrieved 2 March, 2016,from http://dx.doi.org/10.1007/s11205-013-0404-x

Karakuş, D.O., Deniz, M. E., Traş, Z., Eldeleklioğlu, J., Özyeşil, Z., Hamarta, E. (2013). Attitude Perceived by University Students as Predictors of Subjective Well- Being and Life Satisfaction. Psychology PSYCH, Vol.04(03), Pp.169-173.Retrieved on $\quad 20^{\text {th }} \quad$ March, 2016, from http://dx.doi.org/10.4236/psych.2013.43025

Kumar, S. (2014). Emotional maturity of adolescent students in relation to their family relationship. International Research Journal of Social Sciences, Vol.3(3), Pp.6-8.

Marangoni, C \& Ickes, W. (1989). Loneliness a theoretical review with implications for measurement. Journal of Social And Personal Relationships, 6(1), 93-128.Retrieved 13 March, 2016,from http://dx.doi.org/10.1177/026540758900600107

Mohsin, S. M. (1960).A Measure of Emotional Maturity, Psychological Studies. Vol.5(2). Pp. 78-83

Pastey, G. S., \& Aminbhavi, V. A. (2006). Impact of Emotional Maturity on Stress and Self Confidence of Adolescents. Journal of the Indian Academy of Applied Psychology, Vol.32(1), Pp. 66- 70.

Rao, T.V \& Stewart, A.J. (1976). Stewart Maturity Scale (Indian adaptation). (6 ed.).New Delhi: Manasayan.

Seoul, L. J. (1951) Emotional Maturity: The Development and Dynamics of Personality. London: J.B. Lippincott.

Singh, Y. \& Bhargava, M. (1990).Manual for Emotional Maturity Scale (EMS).Agra, India: National Psychological Corporation, Pp.1-13.

Stokes, J. \& Levin, I. (1986). Gender Differences in Predicting Loneliness From Social Network Characteristics. Journal of personality and social psychology, Vol.51(5), Pp. 10691074. Retrieved 23 March, 2016, from http://dx.doi.org/10.1037/0022-3514.51.5.1069

Tumkaya, S, Aybek, B \& Çelik, M. (2008). An investigation of students' life satisfaction and 
loneliness level in a sample of Turkish students. Journal of Human Sciences, 5(1), 1-

15. Retrieved 4 March, 2016, from https://www.j-

humansciences.com/ojs/index.php/IJHS/article/view/429/278

Wagde, A. D. \& Ganaie, S. A. (2013). Study on emotional maturity and coping strategies among the students pursuing rehabilitation studies. International Journal of Science and Research, Vol.2(8), Pp.451-467.

Wan, M.A \& Masih, A. (2015). Emotional Maturity across Gender and Level of Education. International Journal of Indian Psychology, 2(2), 63-72.

Weiss, R. S. (1973). Loneliness: The experience of emotional and social isolation. Cambridge, MA: MIT Press.

Wiseman, H., Guttfreund, D. G. \& Lurie, H. (1995). Gender differences in loneliness and depression of university students seeking counselling. British Journal of Guidance and Counselling, Vol. 23(2), Pp. 231-243. Retrieved 20 March, 2016, from http://dx.doi.org/10.1080/03069889508253008 